about the middle of September last, and may not be deemed uninteresting.

J. M., middle-aged, stout, and generally in good health, while employed in the country, and being much in the open air daily (during September last), had felt languid and more tired at evening than was usual with him, for a few days before being attacked. Previously to his supper-meal, he was seized with severe vomiting and purging. As evening came on, cramp ensued; and a messenger was sent off to sum mon my attendance immediately. On my arrival, he still had vomiting and purging, and was violently affected with cramp in the lower extremities. His voice was husky; the pulse feeble; the skin cold. The stools were watery and bilious-looking. I procured a warm bath with salt in it as soon as possible, and put him into it; but ere long he wished to be out of the bath, on account of the cramp seizing him; and he was put into bed. Still relief he had none; therefore I ordered ice to be got, which was fortunately soon procured from a kind-hearted neighbouring landed proprietor. The ice I applied often in a bladder to the spine of his back ; but, there being no appearance or sign of speedy relief, I gave him the ice to suck internally, and also requested two individuals to take a large piece of ice in each hand and rub the parts cramped. They did so for some time, after which his suffering was much less; and also the motions from his bowels (latterly mucous) had greatly subsided. Nevertheless, as there was considerable coldness of surface, I applied sinapisms of mustard to the calves of the legs and the epigastrium, which induced a normal reaction, and he did well.

\section{NOTES ON CHOLERA.}

By R. W. Watkins, F.R.C.S., Towcester.

[Read at the Annual Meeting of the South Midland Branch, 1859.] [Concluded from page 416. ]

3. Treatment. When the epidemic first commenced, I was induced by what I had read, and by what I had heard from friends who had extensive experience of the disease in large towns, as well as from the successful result of the few sporadic cases which had occurred in my own practice, to place reliance on the calomel and opium treatment. In the earlier cases, it was given in doses of two, three, or sometimes four grains of calomel, and a quarter to half a grain of opium, at intervals more or less frequent, according to the urgency of the case. Observing the rapid passage into collapse of some of these cases, I thought that calomel was too powerful a sedative and that the specific effect of mercury-the restoration of the biliary secretion-might be produced by the hydrargyrum cum cretâ, which might have an equal effect with calomel in checking the vomiting, and which I had already found very successful in diarrhœa, both simple and choleraic. Accordingly, from August 9th to September 6th, the majority of cases were treated with hydrargyrum cum cretâ and opium. Brandy was given frequently in moderate doses; and external warmth was applied by means of hot sand, hot water, mustard plasters, turpentine fomentations, and every other available method. Cold water was given ad libitum, to allay the urgent thirst; and in many cases a weak solution of chlorate of potash was used as a common drink. In the collapse stage, chloric ether was given very frequently, with brandy, and occasionally port wine. In several cases, a mixture of chalk and catechu with opium was given; but in every case it was rejected almost as soon as swallowed, and its use was therefore speedily discontinued. Six cases were treated by dilute sul- phuric acid and opium, which had been found very successful in choleraic diarrhœa; but it was much less so when cholera was fully developed.

At the end of a month, I found that fifty-one cases had been treated with hydrargyrum cum cretâ and opium, of which twenty-four had recovered, and twenty-seven died; five cases had been treated with calomel and opium, of whom two had recovered, and three died-making twenty-six recoveries to thirty deaths under the mercurial treatment with opium. In twenty-one cases, chloric ether had been given, of which twelve had recovered, and nine died. It had, however, been given in many of these cases alternately with mercurials and opium. When given with opium only, the recoveries and deaths were about equal. The hot-air bath was tried in four cases, but all were fatal ; in one only did it give even temporary relief.

The result, then, of our first month's treatment, though very successful in choleraic diarrhœea, was very unsatisfactory when the third stage of cholera (to which alone the above statistics refer) had developed itself. The deaths from the commencement had been as numerous as the recoveries; and, during the last week of the four, they had exceeded them in the proportion of thirteen to nine, showing that the epidemic was increasing both in the number of cases and in severity. I had lost all confidence in the mercurial treatment, both from the unfavourable results, and from having observed that, in the recoveries from collapse, a decided improvement in the symptoms had commenced before the biliary secretion had made its appearance in the evacuations. I had also begun to doubt the propriety of using opium; for although, under the pressure of so large a number of cases of cholera and diarrhœe, we had been unable to take notes of cases (other than the brief memoranda on the prescription-cards), we had not failed to observe that a cessation of the vomiting and purging was by no means an assurance of the patient's recovery, that several cases had died in the collapse stage after the evacuations had ceased, and that some who recovered had continued to vomit and purge (though less frequently) until decided symptoms of reaction had commenced. We had already determined to abandon the mercurial treatment with opium ; my assistant had commenced the use of calomel in small doses every ten minutes, as recommended by Dr. Ayre; and I was using chloric ether and other stimulants.

It was at this period that I read the first letter of Dr. George Johnson, advocating the use of castor-oil, and describing its success in the earlier cases at King's College Hospital. My previous experience seemed strongly to corroborate his views as to the eliminative principle of treatment, and I determined at once to adopt it. In the following twenty-eight cases, castor-oil was administered in twenty-one, generally in doses of two drachms, occasionally of half an ounce, in milk or suspended in mucilage; and the result was that, of the twenty-one cases, nineteen recovered, and two died. Of the other seven cases, five were treated by small doses of calomel every ten minutes, and of these four recovered, and one died; two were treated by hydrargyrum cum cretâ and opium, and both died. I also observe from my memoranda that one case, which had been treated in the second stage with hydrargyrum cum cretâ and opium for two or three days, passed into collapse; that the mercurial treatment was changed for castoroil, and she ultimately recovered.

During the last month of the epidemic, cajeput-oil was used in a large number of cases, either with ether or with castor-oil ; and it certainly had a very remarkable effect in relieving cramps, even when 
opium had failed to do so. But this, I believe, is the limit of its action : it did not appear to check the tendency to collapse. It is certainly a valuable auxiliary remedy.

In four cases, no medicines were taken. One of them was moribund when first visited; another, eighty-two years old, refused medicine, and died. A boy of three and a girl of fourteen obstinately refused medicine, but drank cold water with great avidity; both lay in a state of extreme collapse for a lengthened period, and gradually recovered-the boy without consecutive fever, but the girl's was one of the most severe cases of consecutive fever that we observed.

In the first seven days of September, before the treatment by castor-oil commenced, there were twelve deaths; in the second seven days, five deaths, of which one only had been treated by castor-oil, ten other cases having been treated by it during the week. It will naturally occur to others, as it did to me,-Had not the epidemic reached its acme before the castor-oil treatment was commenced? and was not the more successful result attributable to the modified character of the epidemic, rather than the adoption of an eliminative treatment? I will mention three circumstances which militate against this view. In the first place, it is a very extraordinary coincidence that the mortality, which up to the day of its commencement had continued to increase, should from that day have rapidly diminished. Secondly, during that second week of September when I had just begun to observe the results of the eliminative treatment, I was unexpectedly called in to take charge temporarily of some cases at Silverstone, four miles distant, where cholera had broken out about a week previously, and where it was, consequently, in the period of increase, instead of decline. Two of these cases have such an important bearing on the eliminative theory, that I must narrate them in detail.

CASE r. My unfortunate colleague, Dr. Lett, had previously visited several of my cases at Towcester, and had expressed to me in strong terms his reliance upon opium as the "sheet-anchor" in this disease. Previously to my being called to him, he had treated seven cases by full doses of opium, and every case had died. On September 8th, Dr. Lett, who was much exhausted by his labours and discouraged by his ill success, was further depressed and very anxious in consequence of two of his children being attacked with diarrhœea. During that day he had two liquid evacuations, and on each occasion took a full dose of solid opium. About 8 P.M. he fell exhausted in his own surgery; and, being carried to bed fainting, he sent for me. On my arrival, I found him in a very excited state; he was in extreme anxiety about his own recovery and the prospects of his family; also about the illness of his children. He had no symptoms of cholera, and there had been no evacuation for six hours. I sat with him an hour, quieted and calmed him, and reassured him as far as possible as to his own case. After giving him a cup of coffee, finding him inclined to sleep, I left him to see a very urgent case in the village (Case II). About 12 I returned, found him in a quiet sleep, and at 1 A.M. Ieft him in charge of another surgeon, whom I had summoned from a distant village. He slept quietly till 3 A.M., when he had an evacuation. He immediately got up in great agitation, and, taking some crude opium from his pocket, bit a piece off and swallowed it. From this period to the hour of his death, he had no other evacuation. I received an urgent message to revisit him about 11 A.M., and found he had been in a state of collapse more than an hour, and that stimulants had been freely administered for three or four hours. I immediately administered castor-oil in halfounce doses frequently, and continued moderate stimulants, external heat, ete.; but he never rallied, neither did the castor-oil take any effect. The symptoms gradually increased in intensity till 3 P.M., when he died, having had no evacuation by vomiting, and but one by purging, for twenty-four hours previously.

CASE Ir. A young man, a sawyer, who had gone to his work as usual on the morning of September 8th, had been attacked with diarrhoea, and was brought to Dr. Lett's surgery in a cart about 3 P.M. The collapse stage was then commencing, the hands being blue and shrunken, and the fingers cramped. It was about 11 P.M. when I first saw him; and he was then in a state of extreme collapse, with the most severe cramps I had ever witnessed. I immediately gave him half-ounce doses of castor-oil, repeated every hour, and warm applications to the surface of the body. Three hours later, I again visited him, and found him considerably relieved, the cramps very much diminished, and the warmth of the skin returning. In the morning, he had completely rallied from the stage of collapse; the skin and face had resumed their natural hne, and the cramps had entirely ceased. He had three or four evacuations that day, tinged with bile, and was able to take food. On the following morning (the 10th), he was equally well when first visited; but, having had two evacuations in the course of the morning, he had been incautiously given two pills, the composition of which was not known, but was suspected to be calomel and opium. On visiting him about an hour after the pills had been taken, I found bim, to my great surprise, again in a state of collapse, the surface perfectly blue and shrunken, the voice gone, cramps in the limbs, and rice-water evacuations. I once more administered the castor-oil in frequent doses, and in the course of two or three hours he had again rallied from collapse; the stools were fæculent; and from that time he recovered without consecutive fever or any bad symptom. This was the first case of recovery at Silverstone.

The third reason for my opinion, to which I shall advert, is the fact that the cholera assumed a more virulent character at Tówcester just when we thought it had entirely ceased. There had been no new case for nine days; the old cases were all progressing favourably; I had left home to recruit my strength at the sea-side, when four other cases unexpectedly occurred. The first only (who, like many other cases, had been previously trying "Dr. Coffin's medicine", until cholera was fully developed) was treated with castor-oil for several hours; but, as soon as collapse had set in, it was discontinued, and chloroform in ten-minim doses, and subsequently chloric ether, were given without effect; and the patient died in twentynine hours from the commencement. My assistant, who had not seen the cases at Silverstone, and who attributed the recoveries after castor-oil to the modified character of the disease, and not to the treatment, resorted to frequent doses of calomel, with the addition of chloric ether in collapse; but all the three cases thus treated died.

In conclusion, it is far from my wish to vaunt castor-oil as a specific in cholera; but I do think that the result of the cases thus treated should lead us, if it should ever again be our duty to treat an extensive epidemic of cholera, to use a mild eliminative treatment simultaneously with moderate stimulants, and carefully note the results week by week. For my own part, I have resolved not to administer opium, except, in combination with alteratives, in simple
diarrhcea, in which cases I believe it is certainly of great utility. 